\title{
O RAPTO DE EUROPA: UMA COMPARAÇÃO ENTRE OVÍDIO E TICIANO
}

\author{
THE RAPE OF EUROPA: \\ A COMPARISON BETWEEN OVID AND TITIAN
}

\author{
Márcio Thamos ${ }^{1}$ \\ UNESP - Universidade Estadual Paulista (FCLAr)
}

\begin{abstract}
RESUMO: Nas Metamorfoses, o poeta romano Ovídio narra a fábula da transformação de Júpiter em touro a fim de seduzir a princesa fenícia Europa. Durante o período do Renascimento, como se sabe, a civilização ocidental promoveu uma intensa renovação de seus valores sob a clara influência da cultura greco-romana. Ovídio, cuja fama não cessara por toda a Idade Média, tornou-se então ainda mais conhecido, e especialmente seu poema das Metamorfoses transformou-se em admirável fonte de inspiração não só para a literatura mas também para as artes plásticas e sua nova concepção humanista. Assim, o episódio do rapto de Europa ganhou uma dramática expressão pictórica nas largas pinceladas do mestre veneziano Ticiano Vecellio, que no ápice da maturidade criativa interpretou vários mitos clássicos em suas telas. Entre os versos do antigo poeta latino e o quadro do renascentista italiano há muitas e evidentes relações. Nas Metamorfoses, o relato mítico é descrito em tantos detalhes e fixado numa poética tão expressiva, que Ticiano pôde tomar a narrativa de Ovídio como modelo para pintar "O rapto de Europa", fazendo então um verdadeiro exercício de tradução intersemiótica ao interpretar signos verbais através de signos pictóricos.
\end{abstract}

PALAVRAS-CHAVE: "O rapto de Europa"; Poesia; Pintura; Metamorfoses; Ovídio; Ticiano.

ABSTRACT: In Metamorphoses, the Roman poet Ovid tells the tale of the transformation of Jupiter into a bull to seduce the Phoenician princess Europa. During Renaissance, as is well known, Western civilization fostered an intense renewal of its values under the clear influence of Greco-Roman culture. Ovid, whose fame had not ceased throughout the Middle Ages, became then even better known, and especially his poem Metamorphoses turned into a remarkable source of inspiration not only to literature but also to fine arts and their new humanistic conception. Thus, the episode of the abduction of Europa received a dramatic pictorial expression in the broad brush strokes of the Venetian master Titian Vecellio, who interpreted several classical myths in his canvases at the height of his creative maturity. There are many and obvious relationships in the verses of the ancient Latin poet and the picture of the Italian Renaissancist. In Metamorphoses, the mythical account is described in so many details and set in such an expressive poetic that Titian could take Ovid's narrative as a model for painting "The Rape of Europa", doing a true exercise in intersemiotic translation by interpreting verbal signs through pictorial signs.

${ }^{1}$ Professor da Área de Latim (língua e literatura) do Departamento de Linguística da Faculdade de Ciências e Letras da UNESP, Câmpus de Araraquara, credenciado no PPG em Estudos Literários da mesma Instituição.

Disponível em: http://seer.fclar.unesp.br/casa 
KEYWORDS: "The Rape of Europa”; Poetry; Painting; Metamorphoses; Ovid; Titian.

Compreender é educar o espectador, induzi-lo a compartilhar o ponto de vista do artista.

Kandinsky (2000, p. 31).

\section{Na poesia e na pintura}

Na orla oriental do Mar Mediterrâneo, duas importantes cidades fenícias eram governadas pelo rei Agenor: Sídon e Tiro. Num passado que se perde na memória dos tempos, Europa, a filha do poderoso rei, costumava passear pela praia, onde gostava de se distrair com as amigas. Nesse tempo, Júpiter, o deus que abala o mundo com um simples franzir das sobrancelhas, apaixonou-se pela bela princesa. Transformando-se num magnífico touro branco, mistura-se ao rebanho real e vaga pela praia insinuando-se para a jovem. Ela, sem desconfiar de nada, é atraída pela imponente candura e docilidade majestosa do animal. Assim, aproximando-se pouco a pouco, deixa-se tomar de confiança a ponto de montar sobre seu lombo. Desde então, o gracioso touro caminha sem mais até a beira do mar. Como se casualmente, adentra alguns passos n'água rasa e, de repente, corre decidido de encontro às ondas, carregando consigo a apavorada presa, rumo à ilha de Creta.

O rapto de Europa, famoso mito da Antiguidade Clássica, ganhou a mais conhecida de suas expressões literárias no estilo vigoroso de Públio Ovídio Nasão (43 a. C.17 d. C.). Nas Metamorfoses, o poeta latino apresenta, em quinze livros (a que chamaríamos propriamente cantos ou capítulos), uma longa série de acontecimentos encadeados em que desfilam os principais mitos gregos e romanos. A impressionante arquitetura da obra dispõe, em sucessão contínua, cerca de duzentos e cinquenta episódios variados (CONTE, 1999), escritos apenas em versos hexâmetros ${ }^{2}$. Forma-se assim um vasto conjunto de narrativas tradicionais sobre os deuses, os heróis e os homens, num extenso poema que segue entretecendo histórias desde a criação do mundo até a contemporaneidade do autor. Tratandose de contos mitológicos, discorre-se efetivamente sobre eventos que, de um modo ou de outro, envolvem metamorfoses, de acordo com os versos iniciais do poema ${ }^{3}$ :

Formas que em novos corpos se transformam

- eis o que tenho em mente aqui narrar.

Ó deuses, já que vós as transformastes,

soprai-me os versos, vinde impulsionar

um canto ininterrupto desde a origem

mais remota do mundo até o meu tempo ${ }^{4}$.

É nesse contexto imaginativo, de acordo com o projeto deliberado de fazer rememorar tais eventos míticos em sequência progressiva na história do mundo, que o poeta

\footnotetext{
${ }^{2} \mathrm{O}$ hexâmetro é o modelo de verso tradicionalmente empregado nas epopeias clássicas, tais como a Ilíada e a Odisseia de Homero ou a Eneida de Virgílio.

${ }^{3}$ Note-se que esses versos correspondem a uma verdadeira proposição do tema e invocação às divindades, expediente comum às epopeias. Embora não seja uma obra de assunto guerreiro, ressalta-se aí, estruturalmente, por semelhança àquelas, o caráter das Metamorfoses como um longo poema narrativo de cunho mítico.

${ }^{4}$ Met., I, 1-4 (cf. OVIDE, 1985). A tradução das citações, quando não explicitamente indicado nas Referências, é de responsabilidade do autor deste trabalho.
} 
romano insere a fábula da transformação de Júpiter (equivalente latino do grego Zeus) em touro a fim de seduzir a princesa fenícia, por quem estava tomado de um amor ardente.

O poeta Manuel Maria Barbosa du Bocage (1765-1805), eminente neoclássico português, dedicou-se, em dado momento de sua vida, à tradução de vários trechos selecionados das Metamorfoses, dentre eles, o que traz a narrativa do rapto de Europa. Em sua tradução decassilábica, Bocage operou breves adaptações nos versos iniciais e finais do texto original $^{5}$, a fim de dar autonomia ao episódio, que aparece então intitulado como "O roubo de Europa por Júpiter":

O grão Jove ${ }^{6}$ no Céu Mercúrio ${ }^{7}$ chama,

E sem lhe declarar o amor, que o fere,

"Vai, ministro fiel dos meus decretos,

Vai, filho meu, coa sólita presteza;

Desce à Terra (lhe diz) donde se avista

Tua mãe reluzindo à sestra parte ${ }^{8}$,

E que os seus naturais Sídon nomeiam.

$\mathrm{O}$ armentio real, que ao longe a relva

No monte anda a pascer, dirige à praia".

Disse, e já da montanha o gado expulso

Caminha à fresca praia, onde costuma

A do sidônio rei mimosa filha

Espairecer, folgar coas tírias virgens ${ }^{9}$.

A majestade, e amor não bem se ajustam:

Jamais o mesmo peito os acomoda.

Do cetro a gravidade enfim depondo

O pai, e o rei dos deuses, Jove, aquele

Que armada tem do raio a sacra destra,

E que ao mínimo aceno abala o mundo,

Veste forma taurina entre as manadas

Muge, e pisa formoso as brandas ervas.

É cor da neve, que nem pés calcaram,

Nem coas asas desfez o Sol chuvoso;

Alteia airosamente o móbil colo;

Das espáduas lhe pende, e bambaleia

A cândida barbela, as breves pontas

De industriosa mão lavor parecem,

Ganham no lustre à pérola mais pura.

Não tem pesado cenho, olhar terrível,

Antes benigna paz lhe alegra a fronte.

A filha de Agenor admira o touro,

Estranha ser tão belo, e ser tão manso.

Ao princípio, inda assim, teme tocar-lhe;

Vai-se depois avizinhando a ele,

$\mathrm{E}$ as flores, que apanhou, lhe aplica aos beiços.

Ei-lo já pela relva salta, e brinca,

Já põe na fulva areia o níveo lado.

\footnotetext{
${ }^{5}$ Met., II, 836-875; III, 1-2 (cf. OVIDE, 1985).

${ }^{6}$ O grão Jove: o grande Júpiter, rei dos deuses.

${ }^{7}$ Mercúrio: o mensageiro dos deuses, especialmente de Júpiter, seu pai.

${ }^{8}$ A mãe de Mercúrio é Maia, uma das Plêiades, que foram metamorfoseadas em estrelas.

${ }^{9}$ As moças sidônias podem ser chamadas tírias devido à estreita relação entre as cidades de Sídon e Tiro.
} 
À virgem pouco a pouco o medo extingue,

E agora of'rece brandamente o peito

Só para que lho afague a mão formosa,

Agora as pontas, que a real donzela

De recentes boninas lhe engrinalda.

Ela, enfim, que não sabe a que se atreve,

Ousa nas alvas costas assentar-se.

De espaço à beira-mar descendo o Nume,

Põe mentiroso pé n'água primeira,

Vai depois mais avante... enfim, nadando,

Leva a presa gentil por entre as ondas.

Ela de olhos na praia, ela medrosa

Segura uma das mãos numa das pontas,

Sobre o dorso agitado a outra encosta;

Enfuna o vento as sussurrantes vestes.

Despida finalmente a falsa imagem,

Eis aparece o deus, eis brilha Jove,

E em teus bosques, ó Creta, Amor triunfa!

(OVÍDIO, 2007, p. 99 e 101).

As Metamorfoses atravessaram os tempos como um verdadeiro tesouro literário em que se preserva o saber genuíno e a força poética da mitologia clássica. Por vezes, na esteira de estudiosos tradicionais, como Edith Hamilton (1942), querem acusar Ovídio de "frívolo" (p. 17) e, revelando certa ingenuidade crítica, assumem o inconsistente argumento de que, em se tratando de mitologia, os romanos não são confiáveis como "os escritores gregos, que acreditavam no que escreviam" (p. 18)... Mas a própria autora, que afirma ter evitado "tanto quanto possível" usar o poeta romano em seu famoso manual de mitologia, não deixou de admitir que

A maioria dos livros sobre histórias da mitologia clássica dependem principalmente do poeta latino Ovídio, que escreveu durante o reinado de Augusto. Ovídio é um compêndio de mitologia. Nenhum escritor antigo pode-se comparar a ele quanto a esse respeito. Ele contou quase todas as histórias e contou-as longamente. Às vezes, histórias que nos são familiares através da literatura e da arte chegaram até nós apenas em suas páginas. (HAMILTON, 1942, p. 15).

Durante o período da Renascença, nos séculos XV e XVI, como se sabe, a civilização ocidental promoveu uma intensa renovação de seus valores sob a clara influência da cultura greco-romana. Ovídio, cuja fama não cessara por toda a Idade Média, tornou-se, então, ainda mais conhecido, e especialmente seu poema das Metamorfoses transformou-se em exuberante fonte de inspiração não só para a literatura mas também, notadamente, para as artes plásticas e sua nova concepção humanista. Uma diferença marcante entre esses dois períodos históricos com relação à herança clássica é o fato de que no Renascimento os artistas estavam propensos a aceitar o modelo grego e romano, fundado na expressão da beleza natural, em sua organicidade própria, enquanto na época Medieval havia a tendência dominante de adaptar o modelo clássico às convenções contemporâneas ditadas pelos temas caros à religiosidade cristã. Desse modo, conforme observa Panofsky (2002, p. 85), 
Um desenho de Dürer ${ }^{10}$, copiado de um protótipo italiano, provavelmente durante sua primeira estada em Veneza, enfatiza a vitalidade emocional que não existia na representação medieval. A fonte literária que Dürer usou para seu Rapto de Europa não é mais um texto em prosa em que o touro é comparado a Cristo e Europa à alma humana, mas os próprios versos pagãos de Ovídio, revividos em duas estâncias deliciosas de Ângelo Policiano.

Sem dúvida, pois, "A história da arte renascentista italiana é rica em imagens inspiradas nas fábulas das Metamorfoses de Ovídio, 'poemas' pictóricos de Pollaiuolo, Botticelli, Correggio e Ticiano, entre outros" (BAROLSKY, 1998, p. 451). E assim, o episódio do rapto de Europa ganhou uma dramática expressão nas largas pinceladas de Ticiano Vecellio (c. 1485-1576), que no ápice da maturidade criativa interpretou vários mitos clássicos em suas telas, na série por ele mesmo denominada "poesias". O grande mestre veneziano, contemporâneo de Michelangelo (1475-1564) e Rafael (1483-1520), tornou-se um dos maiores expoentes da arte renascentista. Ele dominava todos os ramos da pintura e revolucionou a técnica a óleo com sua pincelada livre e expressiva. Sua influência sobre os artistas posteriores foi profunda (CHILVERS, OSBORNE, FARR, 1988 - "Titian"). A originalidade de Ticiano no tratamento dado aos temas retratados - valendo-se de tonalidades vigorosas, explorando a vivacidade das cores e o contraste entre a luz e as sombras, empregando a oposição de tons quentes e frios, procurando apreender a variação da luminosidade e seus efeitos sobre os objetos -, permite mesmo apontá-lo como um dos precursores do estilo impressionista que se desenvolveria bem mais tarde, no século XIX. Nas palavras de Giulio Carlo Argan (2003, p. 154),

Pela primeira vez, com Ticiano, a pintura não é mais representação indiferente ou comovida, impassível ou patética, mas um fragmento de realidade, um pedaço palpitante de vida vivida, que quer pôr-se em relação com a nossa, constrangê-la a realizar-se com a mesma, dramática intensidade.

Observe-se $O$ rapto de Europa, pintado por Ticiano (figura 1) ${ }^{11}$. Entre a narrativa do antigo poeta latino e o quadro do renascentista italiano, como se percebe, há evidentemente muitas relações. Explicitar alguns dos vínculos formais que ligam essas duas obras numa comparação, ainda que sem qualquer pretensão exaustiva, pode ser útil à medida que oferece uma invulgar oportunidade para a compreensão de certos recursos expressivos empregados de maneira análoga tanto pelo poeta quanto pelo pintor. Aqui, vale sempre lembrar, com I. A. Richards (1971, p. 124), que "a comparação e a elaboração de analogias não envolvem um esforço em fazer uma arte legislar por outra ou obscurecer suas diferenças ou destruir sua autonomia". Trata-se, antes, de procurar estabelecer equivalências que, uma vez bem apreendidas, possam ampliar a compreensão de um e outro sistema de expressão, permitindo certo esclarecimento mútuo a partir de um diálogo formal entre as obras.

\footnotetext{
${ }^{10}$ Albrecht Dürer (1471-1528), célebre pintor e gravador alemão.

${ }^{11}$ O pintor flamengo Pedro Paulo Rubens (1577-1640), grande mestre do barroco, reproduziu, ao longo da carreira, vários quadros de Ticiano. Dessas cópias feitas por Rubens, uma das mais famosas é justamente a d' $O$ rapto de Europa (1628-1629), o que atesta a originalidade marcante da obra do mestre renascentista (por vezes, em sites na Internet, essa cópia de Rubens aparece creditada a Ticiano - um detalhe significativo, que permite distingui-las facilmente, é o rosto do touro, de traço bem mais reto e duro na tela do artista flamengo, quando comparado ao original do veneziano).
} 


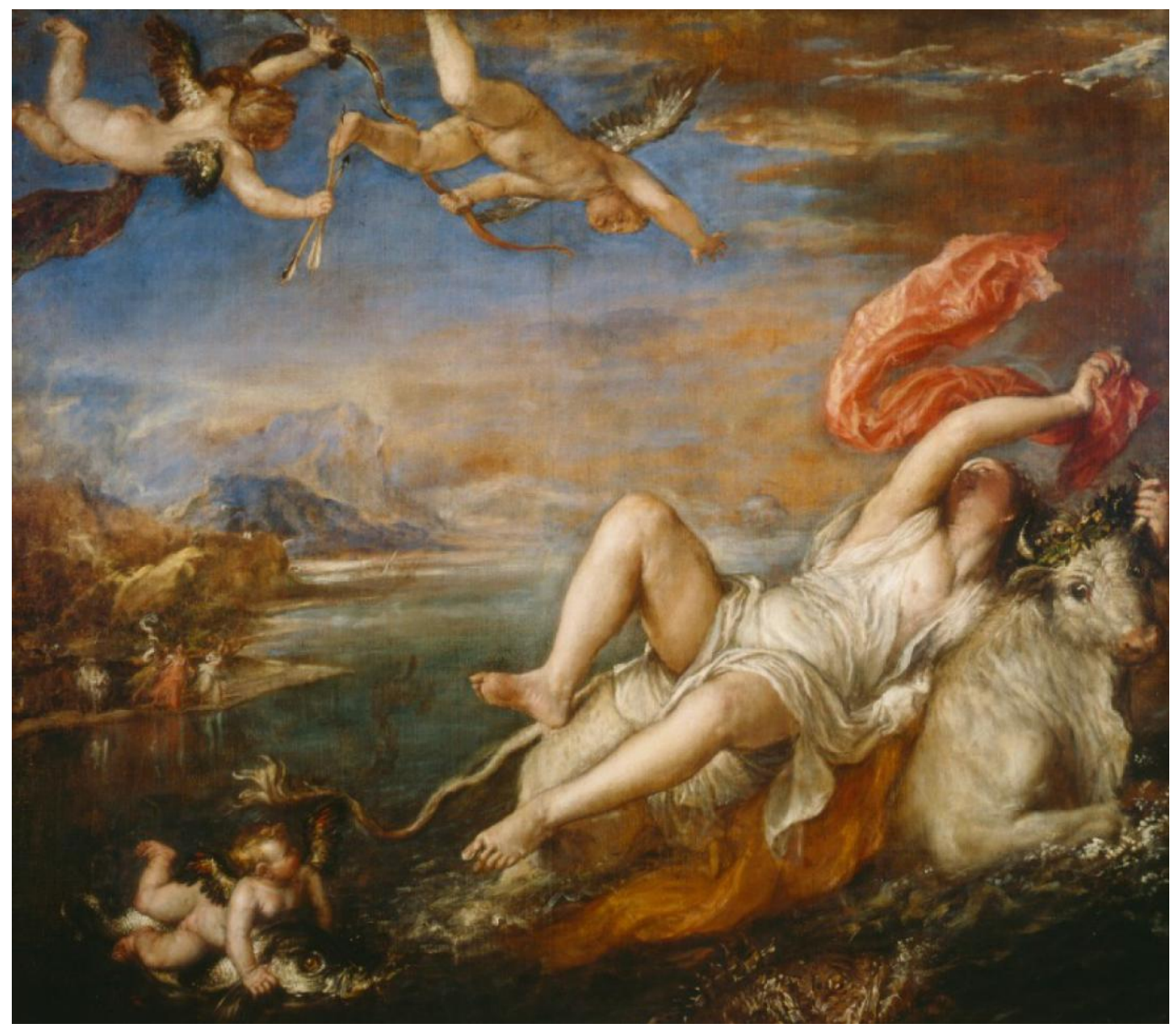

FIGURA 1. Ticiano Vecellio. O rapto de Europa (1560-62).

\section{Mito e narrativa}

Desde a Antiguidade, é bem conhecida a estreita relação entre o mito e a poesia. Toda a literatura clássica se desenvolveu a partir dessa rica fonte de criação popular e coletiva que é a mitologia, apropriando-se de seus temas e fixando-os em obras particulares que atravessaram os séculos. Mas também a pintura, seguindo os desígnios da escultura (e de certo modo os aprofundando), foi desde sempre um veículo de expressão do imaginário mítico, como se pode constatar nos numerosos afrescos que decoravam as casas de Herculano e de Pompeia $^{12}$, nos quais as cenas relacionadas à mitologia greco-romana são temas dominantes. Portanto, em primeiro lugar, é preciso ter em mente que o mito em si, isto é, a narrativa tradicional de caráter fantástico e simbólico transmitida oralmente de geração a geração como um tesouro de cultura, enfim, a fábula arquetípica que permanece como criação do espírito coletivo, não se confunde, ou pelo menos não se identifica inteiramente, com sua expressão artística. As obras de arte que o mito inspira, quer sejam literárias quer sejam

\footnotetext{
${ }^{12}$ Duas cidades da antiga Itália, na região da Campânia, que foram completamente soterradas pela erupção do Vesúvio, no ano 79 d. C., e assim permaneceram até serem descobertas por escavações arqueológicas, já no século XVIII.
} 
plásticas, podem ser vistas como representações particulares do relato mítico, estabelecendo com ele relações de tipo bastante diverso.

Nessas representações, nem sempre se percebe uma especial preocupação com o aspecto narrativo do mito, sua configuração característica como relato de acontecimentos passados num tempo imemorial. Ao contrário, ele, o mito, pode muitas vezes ser tratado de forma tão somente referencial ou alusiva, como na pintura que apresenta uma figura isolada, por exemplo, Orfeu tocando a lira, ou no poema que faz simples menção a determinada história mítica sem, no entanto, contá-la de fato, explicitando seu enredo.

Nas Metamorfoses, no entanto, o relato mítico é descrito em tantos detalhes e fixado numa poética tão expressiva, que Ticiano pôde tomar a narrativa de Ovídio como modelo para pintar $O$ rapto de Europa ${ }^{13}$. Desse modo, um importante aspecto que se quer aqui ressaltar é justamente o caráter narrativo do episódio registrado em versos, para em seguida verificar de que maneira se mantém na tela essa qualidade estrutural do texto a partir das sugestões figurativas que ele projeta. Será preciso, pois, observar como se pôde construir de fato certa equivalência de valores e significações entre sistemas de signos de natureza diferente a fim de se contar uma mesma história. Para tanto, é insuficiente a imediata constatação de que o poema narra a lenda da princesa e do touro branco e de que no quadro se apresentam em destaque justamente essas duas figuras principais. Esse fato por si só não cria na tela a noção de uma narrativa, isto é, não sugere uma sequência de imagens que mostre o desenrolar dos acontecimentos. Do mesmo modo, não basta a simples constatação de que elementos simbólicos, tradicionais na pintura, que aparecem em torno das figuras principais, contribuem para a noção narrativa da composição, tais como os cupidos, figurativizando o tema da paixão, e os peixes, relacionáveis à ideia de fecundidade ${ }^{14}$.

Em um notável afresco de Pompeia conhecido como "Europa e o touro" (figura 2), por exemplo, não se percebe o aspecto narrativo do mito como nitidamente se vê no quadro de Ticiano (naquela antiga representação, aliás, o touro nem sequer é branco nem tem os chifres enfeitados de flores, detalhes figurativos que não interessaram ao pintor anônimo da "Casa de Jasão"). Do mesmo modo, em várias outras pinturas, já da época moderna, que tratam do mesmo tema, claramente sob a influência de Ovídio (o touro, então, dificilmente deixa de ser branco ou de trazer coroas de flores que o adornem), o caráter narrativo do mito não é particularmente ressaltado como na tela do mestre veneziano. A título de exemplo, observe-se em comparação o gracioso quadro de Simon Vouet (1590-1649), célebre pintor do barroco francês, em que a princesa se recosta muito à vontade sobre o dorso do touro (figura $3)$.

\footnotetext{
${ }^{13}$ Nos Fastos (V, 599-620), Ovídio faz também referência à fábula da transformação de Júpiter em touro a fim de raptar a princesa fenícia, mas numa descrição bem mais abreviada (cf. OVIDE, 2003).

${ }_{14}$ De acordo com o Dicionário de Símbolos de Chevalier e Gheerbrant, "em função de sua prodigiosa capacidade de reprodução e do número infinito de suas ovas" (1991, p. 704 - "peixe"). 
CASA, Vol.10 n.2, dezembro de 2012

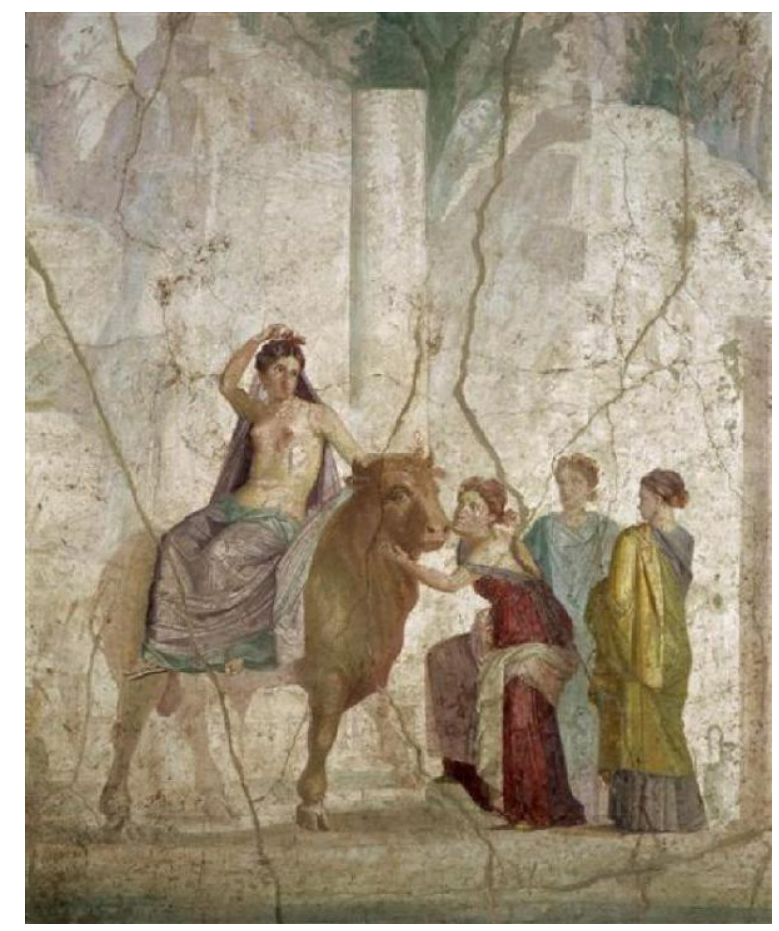

FIGURA 2. "Europa e o touro" (séc. I d. C.).

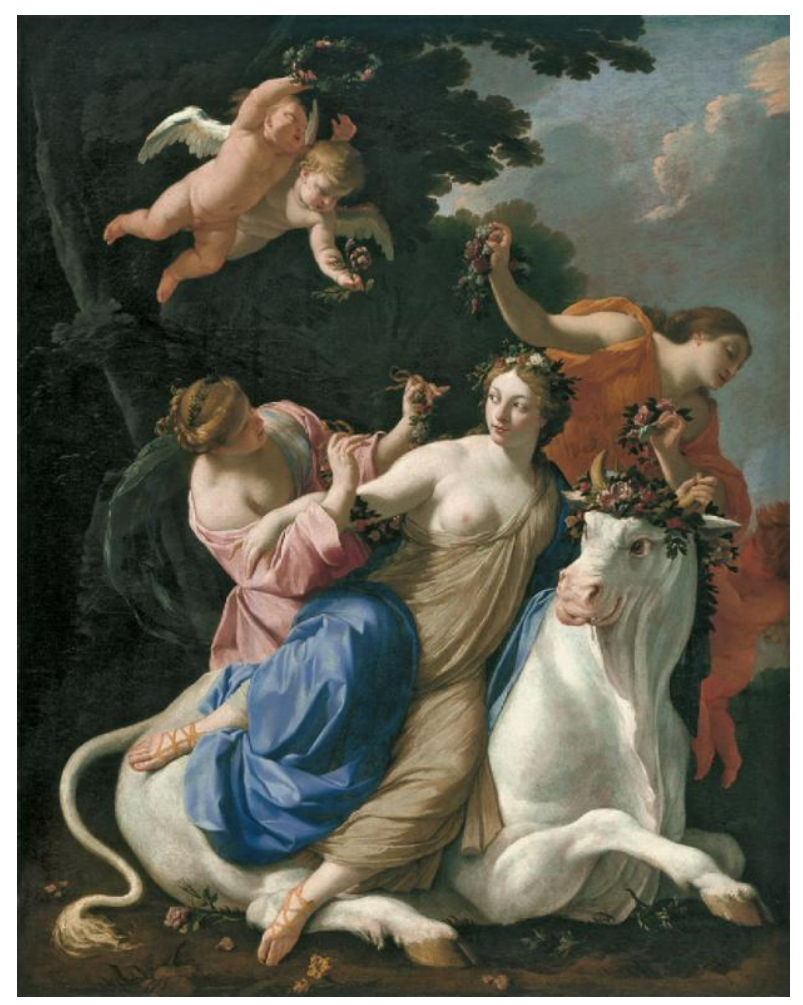

FIGURA 3. Simon Vouet. O rapto de Europa (c. 1640). 
maneiras.

Sabe-se que, na pintura, o efeito de movimento pode ser produzido de diversas

Enquanto observamos, por exemplo, o flexionamento de um braço, o olho recebe uma série de sucessivas e modificantes impressões na retina. Certas combinações dessas, as quais representam não a posição e a forma do braço num instante qualquer mas um compromisso ou fusão de diferentes posições e formas, têm uma capacidade facilmente explicável para representar toda a série, e assim representar o movimento. (RICHARDS, 1971, p. 131).

Na pintura de Ticiano, a figura do touro projeta-se quase para fora da moldura, prestes a sair da tela pela margem direita do quadro, como se num piscar de olhos pudesse desaparecer da vista do espectador. Trata-se aí, como se percebe, de um expediente que acentua a sensação de velocidade com que Júpiter nada ao raptar a princesa, dando maior relevo e vivacidade à sugestão de movimento ${ }^{15}$. Mas o mestre veneziano não se limita a fazer o retrato de figuras em movimento num dado instante que puramente refira o mito ou a ele se reporte por simples alusão; ao contrário, na própria escolha da cena e na maneira como ela é retratada, procura sugerir não só o movimento das figuras, mas ainda a narração completa do mito, como se pode ler em Ovídio.

Para Hegel (1954, p. 19), a pintura reúne em uma mesma obra o que pertencia a duas artes distintas: "o ambiente exterior, que a arquitetura modelava artisticamente, e a forma humana, representada pela escultura", pois,

A pintura coloca suas figuras em meio a uma natureza exterior que ela cria no mesmo sentido, ou em meio a um ambiente arquitetônico. Ademais, sabe fazer desses objetos exteriores, pelo sentimento e alma da concepção, um reflexo do espírito, ao mesmo tempo que os põe em relação e em harmonia com a expressão das figuras que se movem em seus quadros.

À pintura, pela própria fluidez de seus meios, a fim de buscar uma expressão mais viva e significativa, é "não só permitido, senão prescrito, adotar uma vitalidade dramática, agrupar as figuras de modo que as mostre atuando em uma situação determinada" (HEGEL, 1954, p. 94). Assim, a narrativa de Ovídio e os detalhes expressivos com que o poeta nos conta o mito sugerem a Ticiano a dramaticidade que interessava ao seu estilo próprio. Note-se que, fugindo a qualquer noção de imobilidade, o pintor escolhe não um momento da narrativa em que as personagens estejam, por assim dizer, casualmente em movimento, mas procura captar o exato instante de ação mais vigorosa, o que lhe permite a expressão dos sentimentos com grande intensidade - destaca-se então o rosto assustado da jovem, que olhando para o céu revolto descobre os cupidos, em contraste com o olhar tranquilo do touro, isto é, do próprio Júpiter, que encara significativamente o espectador. Aliás, o semblante do animal tem traços muito suaves, bastante arredondados, o que realça a expressão bondosa, em perfeita consonância com o texto de Ovídio, quando, na tradução de Bocage, assim descreve o touro: "Não tem pesado cenho, olhar terrível,/ Antes benigna paz lhe alegra a fronte". E o desespero da princesa raptada se expressa não só em seu rosto, mas em toda sua postura corporal; além disso, a mantilha vermelha que traz na mão direita,

\footnotetext{
${ }^{15}$ Claude Monet (1840-1926) empregou recurso semelhante na composição da tela A canoa sobre o Epte (c. 1890), que pertence ao acervo do Museu de Arte de São Paulo. Nesse quadro, a figura da leve embarcação é literalmente cortada pela moldura direita, enfatizando-se assim a impressão de seu deslizamento sobre as águas do rio.
} 
ondulante ao vento, revela não apenas sua procedência nobre, mas sobretudo seu estado de espírito, vacilante entre o susto e o arrebatamento da sedução. Quanto ao aproveitamento expressivo das cores, é interessante notar que o branco do touro é o mesmo que veste Europa. Tal procedimento funde plasticamente, por contiguidade na tela, as duas figuras, reforçando de maneira admirável sua ligação. Desse modo, o presente instantâneo então retratado já aponta para a conjunção futura dos dois amantes.

\section{O mito em perspectiva}

Para além do relevo dramático, é notável que a escolha de tal cena não se dá apenas pela oportunidade que oferece de apresentar o momento de maior tensão no desenrolar da fábula, mas, sobretudo, pela virtude precisa que tem de condensar significativamente, em uma única imagem, todo o percurso narrativo do mito - eis o que aproxima com clareza Ticiano de Ovídio.

Conforme observa Hegel (1954, p. 96),

A pintura não pode oferecer o desenvolvimento de uma situação, de um acontecimento, de uma ação, como a poesia ou a música, em uma sucessão de estados diversos, senão em um só momento. Daí nasce uma reflexão simples, e é a de que o conjunto da situação ou da ação, de certo modo sua essência, deve representar-se por este único instante. Por conseguinte, é preciso eleger o momento no qual o que precede e o que segue se concentram em um único ponto.

Assim, o pintor deve selecionar, dentre as possibilidades figurativas que o enredo lhe põe à disposição, um instante especial capaz de mostrar a série de ações encadeadas que formam o acontecimento como um todo, um instante no qual a narrativa inteira se resume e através do qual se pode sugerir a sucessão de imagens que a compõem antes e depois desse preciso instante - um momento em que se dá a ver ainda o passado, ao mesmo tempo que o futuro se projeta no presente fugaz fixado na tela. Em outras palavras, vale dizer que, nesse caso, a fim de poder representar a ocorrência sequencial de eventos parciais que compõem um todo narrativo, a pintura, bem como as demais artes plásticas, que por definição se insere no campo das "artes espaciais", deve necessariamente incorporar a seus meios de expressão características próprias das chamadas "artes temporais", como a poesia e a música. É de fato o que faz Ticiano em sua transposição d'O rapto de Europa a partir do poema de Ovídio, buscando "a equivalência na diferença", alicerce e ponto de partida para todo tipo de tradução - seja interlingual, intralingual ou intersemiótica -, conforme o clássico postulado de Roman Jakobson (2001, p. 64-65) ${ }^{16}$.

Tendo em mente tais considerações, perceba-se que na tela do mestre veneziano, há um movimento narrativo que se constrói claramente da esquerda para a direita, isto é, da praia, onde estão "as tírias virgens" para o alto-mar, onde aparece o touro branco que "Leva a presa gentil por entre as ondas". Tal percurso se insinua com toda a força pelo uso particularmente expressivo da perspectiva linear nesse quadro, impondo-lhe de maneira indelével a marca da temporalidade.

\footnotetext{
${ }^{16}$ E caberia aqui uma explicitação dessa ideia: quando se diz que a tradução busca "a equivalência na diferença", pode-se entender que o que se procura é uma equivalência de significação na diferença contextual de signos.

Disponível em: http://seer.fclar.unesp.br/casa
} 
A perspectiva linear, que passou a ser estudada sistematicamente a partir do Renascimento, é um recurso de base matemática que produz o efeito de profundidade no desenho, simulando a impressão visual de afastamento ou aproximação entre objetos representados num mesmo plano. Assim, as figuras que são, na verdade, postas ao lado umas das outras, diminuem ou aumentam de tamanho na tela, de acordo com a sensação de distanciamento real no espaço percebida pelos olhos (por isso, na descrição de pinturas é usual a distinção entre "primeiro plano" (representado abaixo na tela) e "fundo" (representado acima na tela). Vale dizer que a perspectiva linear é capaz de comunicar a aparência de realidade tridimensional a uma superfície bidimensional.

Esse efeito realista da composição pictórica clássica criado a partir da perspectiva linear traz duas consequências fundamentais que interessam diretamente à comparação aqui estabelecida com o texto de Ovídio: cria-se assim um ponto de vista externo, ao mesmo tempo que se desenvolve um verdadeiro processo de montagem de planos, responsável pela própria estruturação narrativa do quadro.

Com relação ao ponto de vista na pintura, atente-se para o seguinte comentário de B. A. Uspênski (1979, p. 170):

Antes de mais nada, a utilização de um ponto de vista interno ou externo manifesta-se no sistema de perspectiva que o pintor aplica. Na realidade, a perspectiva clássica linear (direta) apresenta uma imagem tal como ela é percebida de fora (de lado), com um ponto de vista fixado externamente em relação à realidade representada.

Trata-se, pois, da visão que se teria a partir de uma janela aberta. Esse ponto de vista de um observador externo projetado pelo quadro de Ticiano corresponde perfeitamente ao foco narrativo em terceira pessoa, ou seja, ao ponto de vista de um narrador que se situa fora dos acontecimentos e os transmite, portanto, como se fosse também um observador externo. Não é outra a perspectiva do narrador reconhecível no poema de Ovídio, como se pode facilmente constatar pela leitura do episódio traduzido por Bocage.

Devido aos hábitos culturais e às dominâncias estéticas desenvolvidos pela modernidade ocidental, talvez pareça inteiramente natural ou quase óbvia a perspectiva linear adotada pelo pintor na transposição da narrativa mitológica das Metamorfoses. Mas sabe-se que, na tradição da pintura, nem sempre o ponto de vista externo foi a solução expressiva encontrada pelos artistas para a composição de suas obras. Nesse sentido, citando ainda Uspênski (1979, p. 169), é interessante observar que,

Se, desde os tempos da Renascença, era comum nas artes plásticas europeias a posição externa do artista em relação ao objeto representado, nas velhas escolas de pintura o artista antigo ou medieval situa-se como que dentro do quadro a ser pintado, representando o mundo em sua volta, e sem partir de nenhuma posição alheia - de modo que ela em lugar de ser externa é interna em relação ao quadro.

De um modo geral, pode-se compreender que na pintura o ponto de vista interno corresponde a um tratamento mais subjetivo do tema retratado, uma vez que aí não se busca um efeito de ilusão referencial fundado na imitação minuciosa de caráter realista (como, por exemplo, num quadro em que determinada figura aparece com um tamanho exagerado em relação às outras, recebendo assim maior destaque e importância). Para manterse o paralelo com o texto literário, caberia pensar, nesse caso, em certa aproximação com o 
foco narrativo em primeira pessoa, isto é, com o ponto de vista de um narrador situado dentro dos acontecimentos.

A fixação de um ponto de vista externo e o tratamento objetivo dado ao espaço a partir daí, observando-se a relação proporcional entre as figuras de acordo com a perspectiva linear, acentua naturalmente a noção temporal que se projeta na composição, contribuindo para o efeito de realidade então produzido.

Além do reconhecimento de um ponto de vista externo nas duas obras comparadas, perceba-se que no texto de Ovídio, o tempo da narração é simultâneo aos fatos narrados, isto é, o narrador descreve com vivacidade aquilo que vê no momento mesmo em que a sequência de ações acontece. Assim, comentando o poema das Metamorfoses, Italo Calvino (2002, p. 37) já fez notar que

Ao longo de páginas e mais páginas todos os verbos estão no presente, tudo acontece diante de nossos olhos, os fatos premem-se, toda distância é negada. E, quando Ovídio sente a necessidade de mudar de ritmo, a primeira coisa que faz não é mudar o tempo dos verbos mas a pessoa, passar da terceira para a segunda, isto é, introduzir a personagem sobre a qual está para falar dirigindo-se a ela diretamente com o tu: "Te quoque mutatum torvo, Neptune, iuvenco..."17. O presente não se encontra só no tempo verbal mas é a própria presença da personagem que é evocada. Mesmo quando os verbos estão no passado, o vocativo provoca uma aproximação repentina.

Esse efeito de presentificação dos acontecimentos narrados no poema está também analogamente realçado no quadro de Ticiano por conta da perspectiva linear e da forte sensação de realismo que ela produz.

Contudo, apenas o ponto de vista adotado pelo pintor e o estilo realista de sua tela não explicam por si sós a acentuada noção de temporalidade que advém da cena retratada. É preciso observar ainda o procedimento de montagem responsável por esse dinamismo imagético-narrativo irradiado pelo quadro. A simplicidade do método, quando analisado, chega a ser desconcertante diante do enfático efeito emotivo que um grande mestre dele pode extrair.

O quadro de Ticiano está organizado de modo a dividir a superfície única da tela em planos justapostos que, com o emprego da perspectiva linear, parecem se sobrepor, isto é, na relação proporcional que contraem entre si compondo uma mesma imagem, criam o efeito de profundidade. Assim, vê-se no primeiro plano, ocupando uma grande porção de tela mais à direita e para baixo, com todo o destaque descritivo que o texto de Ovídio lhes confere, o touro branco e a princesa raptada, já em alto-mar. Num segundo plano, à esquerda, preenchendo um pequeno espaço no alto da metade inferior do quadro, mal distintas na distância, postam-se à beira do mar as amigas de Europa, que ficaram na praia, em desespero chamando por ela.

Aqui é interessante notar que Ovídio não se refere diretamente às moças que ficam à beira do mar, como vemos no quadro. Essa sugestão, no entanto, é dada no início da narrativa, quando se diz que a princesa costumava brincar na praia com "as tírias virgens". Ficarem aflitas junto ao mar chamando pela amiga raptada é, pois, uma possibilidade que permanece, por assim dizer, em "segundo plano", isto é, que se infere naturalmente da leitura. Apreendendo com clareza a sugestão, Ticiano atualiza tal possibilidade, e em sua composição

\footnotetext{
17“A ti também, Netuno, transformado em um feroz novilho...” [Aracne representa em seu bordado], verso do episódio sobre a disputa entre Minerva e Aracne; Met. VI, 115 (cf. OVIDE, 1989).
} 
as moças fenícias de fato aparecem "atrás" na perspectiva de planos do quadro, permitindo assim a eloquente expressão da temporalidade narrativa na tela.

Portanto, pondo em grande destaque, no primeiro plano, as figuras do touro e da princesa e acentuando sobremaneira o recuo das moças na praia, no segundo plano, cria-se uma verdadeira sucessão de planos de montagem. A simples justaposição desses dois planos, à direita e à esquerda, já sugere, pela relação de contiguidade, a noção de sequência temporal da narrativa. Trata-se basicamente do mesmo processo estudado por Eisenstein (2002, p. 16) para o desenvolvimento de qualquer narrativa no cinema, cujo princípio assim se enuncia:

[...] a justaposição de dois planos isolados através de sua união não parece a simples soma de um plano mais outro plano - mas o produto. Parece um produto - em vez de uma soma das partes - porque em toda justaposição deste tipo o resultado é qualitativamente diferente de cada elemento considerado isoladamente.

Mas, entenda-se, com o próprio realizador de $O$ encouraçado Potenkim, entre outros filmes marcantes na história cinematográfica, que

Esta não é, de modo algum, uma característica peculiar do cinema, mas um fenômeno encontrado sempre que lidamos com a justaposição de dois fatos, dois fenômenos, dois objetos. Estamos acostumados a fazer, quase que automaticamente, uma síntese dedutiva definida e óbvia quando quaisquer objetos isolados são colocados à nossa frente lado a lado. Por exemplo, tomemos um túmulo, justaposto a uma mulher de luto chorando ao lado, e dificilmente alguém deixará de concluir: uma viúva. (EISENSTEIN, 2002, p. $14)$.

Assim, ao associar duas imagens parciais, mais ou menos autônomas, em sua tela, Ticiano instaura um procedimento de montagem, do qual resulta uma nova qualidade significativa para o quadro. Como produto da relação criada entre os dois diferentes planos, percebe-se o efeito da temporalidade narrativa, que não se poderia entrever em nenhum desses mesmos planos se considerados isoladamente.

Mas não será demais ressaltar ainda que a própria criação dos planos de montagem no quadro do mestre veneziano está fundamentada no uso saliente e contrastante da perspectiva linear, projetando para a frente, quase como a saltar do quadro, o touro com sua presa, ao mesmo tempo que faz retroceder extraordinariamente as moças na praia. Nesse sentido, como exemplo em contraponto, vale observar o fascinante quadro homônimo de Rembrandt (1606-1669), em que tanto Europa e o touro quanto as moças na praia aparecem enquadradas no primeiro plano (figura 4). É notável que a temporalidade narrativa aí já não se impõe com tanta expressividade como na tela de Ticiano. 


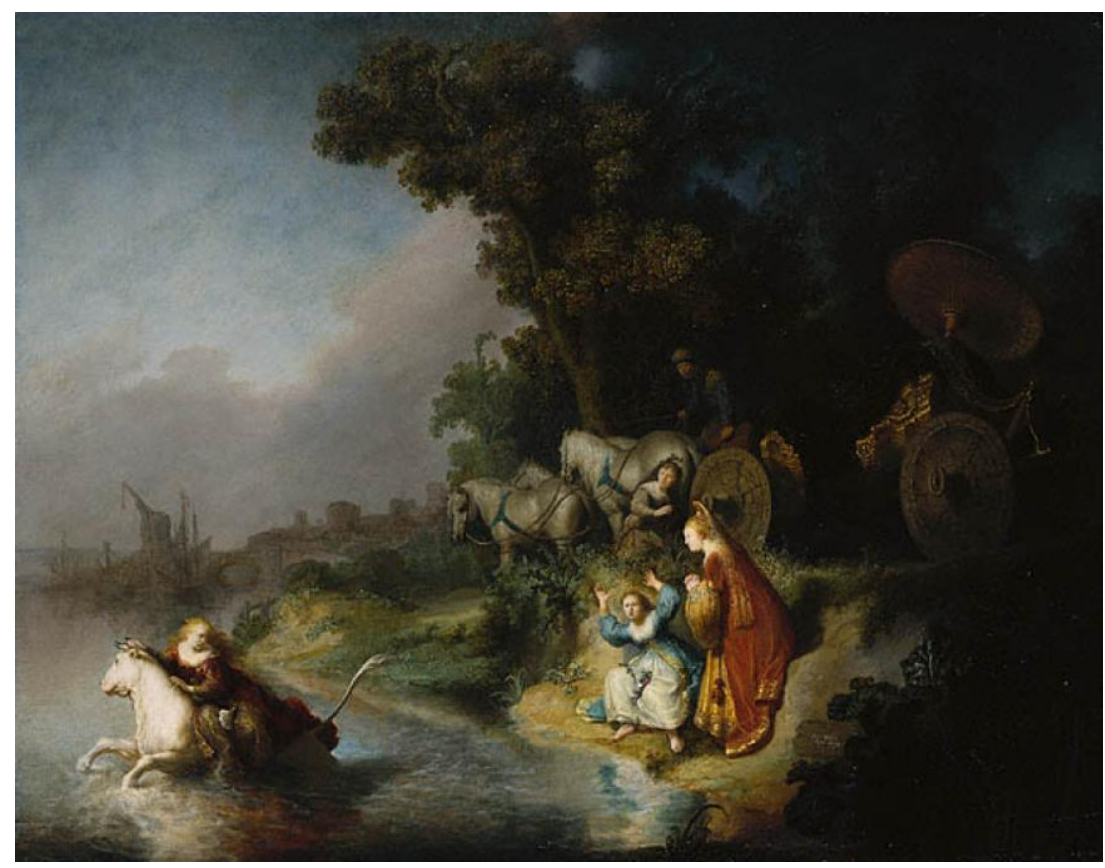

FIGURA 4. Rembrandt Harmensz van Rijn. O rapto de Europa (1632).

Outro detalhe significativo criado pela montagem e reforçado pela perspectiva adotada por Ticiano é, por assim dizer, um "terceiro plano" projetado no quadro, isto é, o fundo ainda mais ao fundo: estendendo-se sobre a linha que delimita o contorno do mar, próximo ao centro da tela, delineia-se a longínqua paisagem de formas indecisas, onde se pode entrever ao menos um navio com a vela aberta. Trata-se aí de aplicação da perspectiva linear, combinada à noção de perspectiva aérea. Esse efeito de traços rarefeitos e difusos, de acordo com a impressão real que se tem dos objetos à distância, envoltos pela atmosfera, é assim descrito por Hegel (1954, p. 84):

[...] quanto mais se afastam da vista, mais os objetos se tornam descoloridos, indeterminados em suas formas, porque a oposição entre luz e sombras se apaga cada vez mais, até que o conjunto se perde em um cinza claro. No entanto, as diferentes maneiras como os objetos são iluminados ocasionam, nesse sentido, os desvios mais variados. Particularmente na pintura de paisagem, e também em todos os demais quadros que representam vastos espaços, é onde a perspectiva aérea é da maior importância. Também aí é onde os grandes mestres do colorido têm produzido efeitos mágicos.

E Ticiano soube explorar esplendidamente as possibilidades da perspectiva aérea n'O rapto de Europa. Percebe-se aí, mais uma vez, o aprofundamento no espaço sugerindo o alongamento no tempo, agora já no sentido de uma perspectiva histórica: a figura do barco, como símbolo fenício, com suas formas esvanecidas, visto em perspectiva "muito ao longe", mas significativamente posto sobre o dorso da jovem carregada pelo touro, marca bem a origem da princesa. Mas, além disso, desempenha uma importante função narrativa na tela, introduzindo índices espaçotemporais, como faz explicitamente o texto de Ovídio. Promove-se assim a contextualização narrativa, a partir da "ancoragem histórica", ao instalarem-se, em termos semióticos, topônimos e cronônimos, "que visam a constituir o simulacro de um referente externo e a produzir o efeito de sentido 'realidade"' (GREIMAS \& 
COURTÉS, 2008, p. 30 - "Ancoragem"), como a dizer: "Num tempo muito distante, na Antiga Fenícia"...

Vê-se, pois, que a técnica de perspectiva empregada pelo mestre veneziano foi aproveitada como importante recurso narrativo em sua tela, acentuando a noção de temporalidade na fixação espacial do drama representado, ao criar um percurso carregado de significados, que se estende entre o primeiro plano e o fundo. Ao pintar $O$ rapto de Europa seguindo sugestões suscitadas pelos versos de Ovídio, Ticiano faz um verdadeiro exercício de tradução intersemiótica, procurando interpretar signos verbais através de signos pictóricos, metamorfoseando, por assim dizer, o poema em quadro.

\section{REFERÊNCIAS}

ARGAN, G. C. História da arte italiana: de Michelangelo ao futurismo (v. 3). Trad. Wilma De Katinszky. São Paulo: Cosac \& Naify, 2003.

BAROLSKY, P. As in Ovid, so in Renaissance Art. Renaissance Quarterly, Chicago, v. 51, n. 2, p. 451-474, 1998.

CALVINO, I. Por que ler os clássicos. Trad. Nilson Moulin. São Paulo: Companhia da Letras, 2002.

CHEVALIER, J. \& GHEERBRANT, A. Dicionário de símbolos: mitos, sonhos, costumes, gestos, formas, figuras, cores, números. $4^{\mathrm{a}} \mathrm{ed}$. Trad. Vera da Costa e Silva et al. Rio de Janeiro: José Olympio, 1991.

CHILVERS, I; OSBORNE, H; FARR, D. (ed.). The Oxford dictionary of Art. Oxford; New York: Oxford University Press, 1988.

CONTE, G. B. Latin Literature. $9^{\text {a }}$ ed. Trad. Joseph B. Solodow. Baltimore: Johns Hopkins University Press, 1999.

EISENSTEIN, S. O sentido do filme. Trad. Teresa Ottoni. Rio de Janeiro: Jorge Zahar, 2002. GREIMAS, A. J. \& COURTÉS, J. Dicionário de Semiótica. Trad. Alceu Dias Lima et al. São Paulo: Contexto, 2008.

HAMILTON, E. Mythology. 26 ${ }^{\text {th }}$ prt. Boston: Little, Brown and Company, 1942.

HEGEL, G. W. F. Estética (tomo II). Trad. de la edición francesa de Charles Bénard por H. Giner de los Ríos. Buenos Aires: El Ateneo, 1954.

JAKOBSON, R. Linguística e comunicação. $18^{\mathrm{a}}$ ed. Trad. Izidoro Blikstein e José Paulo Paes. São Paulo: Cultrix, 2001.

KANDINSKY, W. Do espiritual na arte: e na pintura em particular. $2^{\mathrm{a}}$ ed. Trad. Álvaro Cabral e Antonio de Pádua Danesi. São Paulo: Martins Fontes, 2000.

OVIDE. Les fastes (tome II: livres IV-VI). Texte établi, traduit et commenté par Robert Schilling. Paris: Les Belles Lettres, 2003.

OVIDE. Les métamorphoses (tome I: livres I-V). Texte établi et traduit par Georges Lafaye. Paris: Les Belles Lettres, 1985.

Les métamorphoses (tome II: livres VI-X). Texte établi et traduit par Georges Lafaye. Paris: Les Belles Lettres, 1989.

OVÍDIO. Metamorfoses. Trad. M. M. B. du Bocage (Introd. João Angelo Oliva Neto). São Paulo: Hedra, 2007.

PANOFSKY, E. Significado nas artes visuais. $3^{\mathrm{a}}$ ed. São Paulo: Perspectiva, 2002.

RICHARDS, I. A. Princípios de crítica literária. $2^{\text {a }}$ ed. Trad. Rosaura Eichenberg, Flávio Oliveira e Paulo Roberto do Carmo. Porto Alegre: Globo, 1971. 
CASA, Vol.10 n.2, dezembro de 2012

USPÊNSKI, B. A. Elementos estruturais comuns às diferentes formas de arte. Princípios gerais de organização da obra em pintura e literatura. Trad. Aurora Fornoni Bernardini. In: SCHNAIDERMAN, B. (Org.). Semiótica russa. São Paulo: Perspectiva, 1979, p. 163-218.

\section{ILUSTRAÇÕES}

Figura 1:

TICIANO. O rapto de Europa. 1560-62 (óleo sobre tela, 178 x $205 \mathrm{~cm}$ ). Museu Isabella Stewart Gardner, Boston. Disponível em <http://www.gardnermuseum.org/collection/browse?filter=room:1773 >. Acesso em 15 de julho de 2012.

Figura 2:

Europa e o touro. séc. I d. C. (afresco da "Casa de Jasão", Pompeia). Museu Arqueológico Nacional, Nápoles.

Disponível

em

$<$ http://museoarcheologiconazionale.campaniabeniculturali.it/itinerari-tematici/nelmuseo/collezioni-pompeiane/RIT_RA35?searchterm=europa>. Acesso em 15 de julho de 2012.

Figura 3:

VOUET, Simon. O rapto de Europa. c. 1640 (óleo sobre tela, 179 x 141,5 cm). Museu Thyssen-Bornemisza, Madrid.

<http://www.museothyssen.org/thyssen/ficha obra/48>. Acesso em 15 de julho de 2012.

Figura 4:

REMBRANDT. O rapto de Europa. 1632 (óleo sobre painel). Museu J. Paul Getty, Malibu. Disponível em <http://www.getty.edu/art/gettyguide/artObjectDetails?artobj=1069>. Acesso em 15 de julho de 2012. 